\title{
Physical Exercise in the Management of Erectile Dysfunction in Patients with Heart Failure
}

\author{
Ana Gonzáles, ${ }^{1,2}{ }^{\oplus a l e s ~ d e ~ C a r v a l h o, ~}{ }^{2 \oplus}$ Leonardo Andreato, ${ }^{3 \oplus}$ Sabrina Sties, ${ }^{2 \oplus}$ Anelise Sonza ${ }^{2 \oplus}$ \\ Faculdade Estácio de Sá de Santa Catarina,' São José, SC - Brazil \\ Universidade do Estado de Santa Catarina, ${ }^{2}$ Florianópolis, SC - Brazil \\ Centro Universitário de Maringá, ${ }^{3}$ Maringá, PR - Brazil
}

\section{Abstract}

Erectile dysfunction (ED) is a highly prevalent problem that affects the quality of life, prognosis and survival of patients with heart failure (HF). In the management of ED, physical exercise is a therapeutic strategy that reduces disease-related symptoms and optimizes drug use. However, the repercussions of physical exercise on ED in individuals with HF still need to be elucidated. In this sense, the objective of this study was to evaluate the effects of physical exercise on erectile function (EF) in HF patients. This was a systematic review conducted according to PRISMA guidelines. Patients with HF, male and ejection fraction $\leq 45 \%$ were submitted to physical exercise of different modalities. The search for scientific articles was conducted in the electronic databases (PubMed, LILACS, Cochrane-Library, Science Direct) from the inception until October 2018, according to the $\mathrm{MeSH}$ dictionary descriptors, which were suitable for all databases. Results: Three studies were analyzed, includinng 99 male subjects, age ranging from 53 years $( \pm 7.48)$ to 58 years $( \pm 12)$. Seventy subjects were submitted to a physical exercise program and 29 were in the control group. In all studies, physical exercise showed positive results in the management of ED regardless of erectile dysfunction (ED) classification status and intensity of exercise used. It was concluded that physical exercise of different intensities was considered an effective therapeutic intervention to improve $\mathrm{EF}$ in individuals with HF and ED.

\section{Introduction}

Heart failure (HF) is the final common pathway of cardiovascular diseases and a complex syndrome involving multiple systems. ${ }^{1,2}$

Recently, interest in the investigation of sexual dysfunction (SD) of these individuals has increased because it is considered a clinical problem of high severity and prevalence, ${ }^{3-5}$ with many pathophysiological aspects similar to HF syndrome. ${ }^{6,7}$

Approximately $80 \%$ of patients with HF report SD and $30 \%$ report total abstinence from sexual activity. ${ }^{3-5,8}$ In this context, the correlation between HF and erectile dysfunction (ED) deserves attention, especially considering that sexual function is an important component of quality of life (QoL). ${ }^{5,9}$ Sexual problems are strongly related to worse QoL of HF patients, both men $(52 \%)$ and women $(38 \%))^{10-13}$

Recently, it has been demonstrated that men with $\mathrm{HF}$, younger than 66 years, monogamous, with ejection fraction below $35 \%$ are the individuals who report more difficulties in sexual life. ${ }^{12,14} \mathrm{ED}$ is defined and characterized as the inability to reach out and maintain the erection of the penis for enough time to allow

\section{Keywords}

Cardiovascular Diseases; Heart Failure; Exercise; Physical Finess, Erectile Dysfunction; Aged; Drug Therapy.

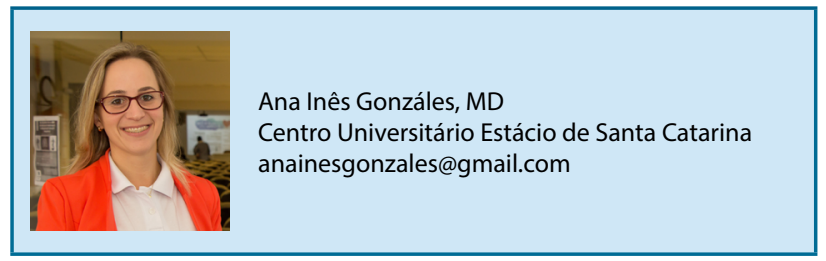

Mailing Address: Ana Gonzáles

Rua Maria Filomena da Silva, 207, apto 208. Postal Code: 88110-630, São José, SC - Brazil.

E-mail: anainesgonzales@gmail.com 
satisfactory sexual intercourse. ${ }^{15,16}$ In men with HF, there is a high prevalence of ED, higher than in healthy men of the same age group (37\% vs 17\%). ${ }^{14}$ ED has been associated with the pathophysiological mechanisms of the HF syndrome and to the side effects of drug treatment. ${ }^{12,13}$ Additionally, the degree of ED can be used as prognosis and survival factor for these patients. ${ }^{9}$

In HF, based on the high level of scientific evidence, physical exercise is a highly recommended therapeutic strategy, ${ }^{17-21}$ with several beneficial effects. ${ }^{22-24}$ In fact, physical exercise was shown to benefit erectile function $(\mathrm{EF}){ }_{,}^{25,26}$ the inflammatory profile $\mathrm{e}^{27-28}$ and the modulation of the autonomic nervous system, ${ }^{29-31}$ promoting improvement in QoL and a reduction in the morbidity and mortality rates of these individuals. ${ }^{32-36}$

However, despite growing interest in the topic, with emergence of many observational studies, ${ }^{3-5,9-14}$ there is still a lack of studies evaluating the effects of physical exercise on $\mathrm{EF}$ of these patients.

In the current knowledge, it seems plausible the hypothesis that physical exercise is a valid therapeutic strategy for ED, by contributing to improvement of the QoL and prognosis of these patients. In addition, physical exercise improves cardiocirculatory performance leading to reduced dyspnea and fatigue symptoms, and less need for drugs. All these variables have been recognized as aggravating factors of SD. ${ }^{12-14}$ Therefore, this study aimed to evaluate the effects of physical exercise on EF in individuals with HF, using a systematic review.

\section{Methods}

\section{Search strategies}

This was a systematic review conducted according to the PRISMA (Preferred Reporting Items for Systematic Reviews and Meta-Analyzes) ${ }^{37}$ recommendations and registered in the PROSPERO platform (International Prospective Register of Systematic Reviews), under the number CRD42018090028.

The search for articles was conducted by two independent researchers in the electronic databases (PubMed, LILACS, Cochrane-Library, Science Direct) databases from inception until October 2018. The study was structured using the PICO - acronym for Population, Intervention, Comparison (since "control" was not applicable to the goal of this study) and Outcomes - framework. ${ }^{37}$

For the search in the PubMed and Cochrane databases, the following MeSH (Medical Subject
Heading Terms) descriptors were used: "Heart Failure" OR "Congestive Heart Failure" OR "Cardiac Failure" AND "Exercise" OR "Exercise Therapy" OR "Aerobic Exercise" OR "Physical Exercise" OR "High-Intensity Interval Training" OR "High-Intensity Interval Training" OR “Resistance Training" OR "Strength Training" AND "Erectile Dysfunction" OR "Sexual Dysfunction, Physiological" OR "Penile Erection" OR "Genital Diseases, Male" OR "Impotence" OR "Sexual Dysfunction, Physiological" (Appendix I). These words were then found suitable for the search in the other databases (LILACS and Science Direct).

In addition, a manual search was carried out for references cited in the articles. Also, a search for "gray" literature was performed in Google Scholar, and in the annals of the World Congress of Cardiology and the European Congress of Cardiology, since they are important events in the area of cardiology with strict selection criteria and representatives from all over the world. We also conducted a search for abstracts, due to the small number of papers on this topic.

\section{Eligibility criteria}

\section{Inclusion criteria}

We included in the review controlled and randomized clinical trials, quasi-randomized controlled trials, comparative studies with or without concurrent controls, case studies, case series with 10 or more consecutive cases, abstracts and articles published in Portuguese, English, or Spanish.

We selected studies with adults (18 years of age or older), with a diagnosis of $\mathrm{HF}$, with reduced ejection fraction ( $\leq$ $45 \%$ ) and functional classes I, II or III according to NYHA. Patients should have been submitted to intervention with aerobic and / or resistance exercise of different intensities. Evaluation of sexual function should have been performed by questionnaires or specific tests: stiffness and nocturnal penile tumescence test, drug-induced erection test, ecodoppler of the cavernous arteries, cavernosography by dynamic infusion, internal pudendal arteriography. ${ }^{38}$ The minimum of 4-week of follow-up time was considered for the time of intervention.

\section{Exclusion criteria}

Letter to the editor, guidelines, systematic reviews and meta-analyses were not included. We also did not include studies on HF patients with comorbidities 
such as renal diseases, cardiac transplantation, chronic obstructive pulmonary disease (COPD), stenosis, ventricular assist devices, and patients using any type of supplementation or experimental medication that could affect sexual function.

\section{Selection of studies}

The selection of studies was conducted by two independent investigators. Studies were initially screened by titles, then by abstracts, and those considered potentially eligible were selected for full reading. The divergences were resolved by consensus.

\section{Data extraction}

Data extraction was performed using a dataset constructed by the researchers; data were added to the dataset by one researcher and then checked by the other researcher. When necessary, the corresponding authors of the studies were contacted to clarify methodological issues or results when necessary or to provide relevant data missing from the abstract or full text.

\section{Assessment of study quality}

For assessment of methodological quality, we used the TESTEX (Tool for the assessment of study quality and reporting in exercise) tool. This instrument was developed specifically for use in exercise training studies. ${ }^{39}$

\section{Results}

\section{Search results}

The flow chart of the search process and results of the search is shown in Figure 1. A total of 318 studies was identified in PubMed, LILACS, Cochrane-Library, Science Direct, and in the Annals of the main scientific conferences in the area. Then, studies were excluded due to duplicity and analysis of the title, abstract and full reading. Finally, three studies met the eligibility criteria.

A total of 99 individuals with HF was included in this review, with mean age ranging from 53 years $( \pm 7.48)$ to 58 years $( \pm 12)$. Of these, 70 individuals were submitted to a supervised aerobic exercise program three times per week, and 29 were controls. In all studies, only males were included, and all patients were in NYHA functional class II $(n=37)$ or III $(n=62)$ and had left ventricular ejection fraction $(\mathrm{LVEF}) \leq 45 \%$.
Of the selected studies, only one randomized clinical trial, conducted in Italy, was published in the format of scientific paper, ${ }^{25}$ while the other two studies ${ }^{26,40}$ were published in Annals of international scientific conferences. The other two studies, in the form of abstracts, were developed in Brazil by the same research group; the first study was a randomized, controlled clinical trial40 and the second one was a uncontrolled, non-randomized prospective clinical trial. ${ }^{26}$

\section{Intervention Protocols}

Regarding the intervention protocols of the selected studies in this review, in the study by Belardinelli et al., ${ }^{25}$ the intervention was supervised exercise training with a cycle ergometer, $3 x$ / week for 8 weeks; each session had a total duration of one hour, divided into 15 minutes of initial stretching, 40 minutes on a cycle ergometer at $60 \%$ of peak oxygen consumption ( $\mathrm{VO}_{2}$ peak) and five minutes of recovery. This study was the only one that used a control group that was not submitted to any type of physical exercise and asked to refrain from exercise during the study period.

Sties et al., ${ }^{26}$ in a prospective study, applied a supervised exercise on a treadmill 3x/week for 12 weeks, with sessions of 40 minutes of aerobic training in which individuals should remain between the anaerobic threshold and the point of respiratory compensation determined by the cardiopulmonary test.

In the randomized clinical trial, Sties et al., ${ }^{40}$ evaluated two groups submitted to different intensities of supervised exercise training on a treadmill. The activity was performed $3 x$ / week for 12 weeks, with sessions of 50 minutes divided in 5 minutes of stretching, 40 minutes of aerobic exercise in the target training zone and 5 minutes of stretching exercises. In this study, the first group $(n=11)$ performed continuous aerobic exercise of moderate intensity and instructed to remain close to the first threshold (aerobic threshold), determined by cardiopulmonary test. The second group $(n=9)$ was submitted to interval aerobic exercise on a treadmill, in a high-intensity protocol, and instructed to remain as long as possible near the second respiratory compensation threshold.

\section{Sexual Function}

For assessment of sexual function, all studies used specific questionnaires. The "Sexual Activity Profile 

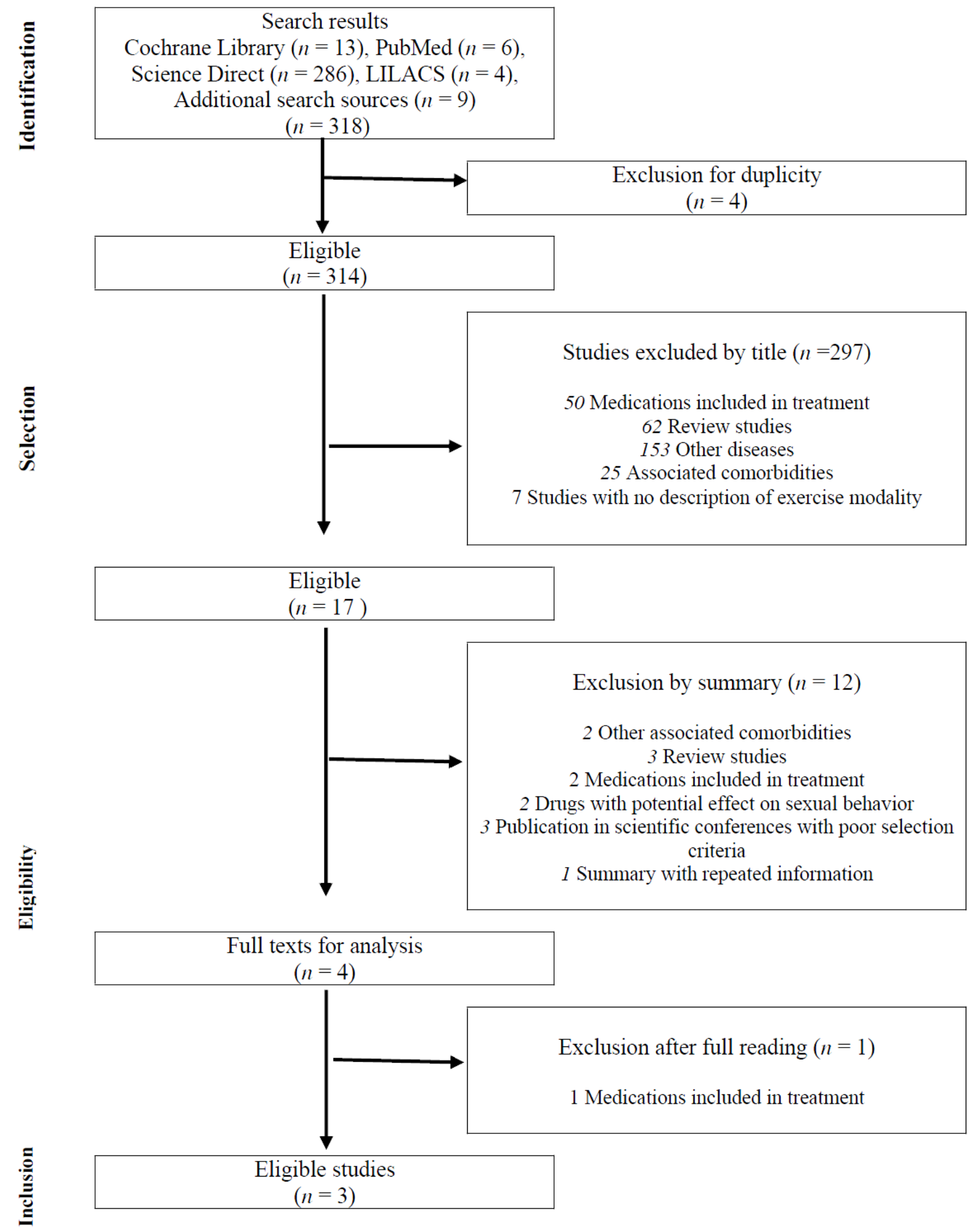

Figure 1 - Flowchart of the search strategy. 
Questionnaire" was used by Belardinelli et al., ${ }^{25}$ and the International index of erectile function (IIEF) in the studies by Sties et al., ${ }^{26,40}$ Belardinelli et al., ${ }^{25}$ investigated only married patients, while in the studies of Sties et al., ${ }^{26,40}$ individuals with an active sex life were evaluated regardless of marital status or monogamy.

Regarding EF, the study by Belardinelli et al., ${ }^{25}$ showed that the exercise group with an intervention of 8 weeks demonstrated a significant improvement in the quality of the erection and in the relationship with the partner. In the study by Sties et al., ${ }^{26}$ the EF domain showed significant improvement after 12 weeks of intervention. In the study by Sties et al., ${ }^{40}$ the significant improvement in the EF score was evidenced only in the group submitted to high-intensity physical exercise training. However, when the results related to the EF classification were verified, both individuals submitted to both high-intensity and moderate training showed significant score increases.

\section{Functional capacity}

In the cardiopulmonary test, Belardinelli et al., ${ }^{25}$ and Sties et al., ${ }^{26}$ demonstrated a significant improvement in $\mathrm{VO}_{2}$ peak. In the study by Sties et al., ${ }^{40}$ the improvement in $\mathrm{VO}_{2}$ peak was evidenced only in the high-intensity interval exercise group. Only in the study by Sties et al., ${ }^{26}$ the six-minute walk test (6MWT) was used and verified that all individuals showed a significant improvement in the walked distance after the intervention.

\section{Endothelial function}

Regarding the endothelial function results, only two studies ${ }^{25,40}$ performed the evaluation of this variable. In the study by Belardinelli et al., ${ }^{25}$ it was possible to observe a significant improvement in the flow-mediated dilation (FMD) of the brachial artery in the group submitted to physical exercise for 8 weeks, at the same time that the FMD was the strongest independent factor of improvement of the sexual function in these patients. For Sties et al., ${ }^{40}$ FMD of the brachial artery did not show a significant improvement in any of the study groups (moderate and high-intensity) after 12 weeks of intervention.

\section{Quality of life}

Assesment of quality of life was performed in two of the three analyzed studies. ${ }^{25,40}$ Both studies used the Minnesota Living with Heart Failure (MLHFQ) questionnaire, validated for patients with HF. There was a significant improvement in the QoL score after physical exercise training in different intensities (high and moderate).

\section{Evaluation of methodological quality}

The eligible studies were fully read and scored based on (Table 2) a structured spreadsheet for data extraction previously designed for the study.

Of the three studies analyzed, $\mathrm{two}^{25,40}$ got the maximum scale score (12 points) (Table 2 ), showing good methodological quality. Only one study showed a low score of 6 points, due to its design nature (uncontrolled, non-randomized longitudinal clinical trial). ${ }^{26}$ The lack of intention-to-treat analysis was verified in all studies, indicating a methodological limitation.

\section{Discussion}

All studies from this review evaluated sexual function through validated and self-reported questionnaires. Physical exercise led to improvements in EF regardless of the degree of dysfunction.

Sexual dysfunction is an increasingly common problem in the middle-aged world population, strongly associated with cardiovascular disease. ${ }^{5,8,15}$ Its high prevalence in HF patients is understandable, since SD and HF have common risk factors and pathophysiological characteristics. ${ }^{3}$ Also, some drugs used in the treatment of HF seem to impair sexual function. ${ }^{41}$

Between $58 \%$ and $87 \%$ of patients report problems in sexual function after the diagnosis of HF. ${ }^{12,42,43}$ These problems may vary from a decrease in the interest and frequency of sexual activity to total abstinence, reported by $25 \%$ of these individuals. ${ }^{13}$ Despite the high prevalence of SD in subjects with HF with concomitant worsening in the QoL indexes, few studies or relevant data on the topic ${ }^{44}$ have been published.

In this context, ED stands out as the most prevalent sexual alteration in patients with $\mathrm{HF}^{3,14,15}$ and it influences not only the QoL but also the prognosis and the survival. ${ }^{9}$ of these patients. Therefore, it is imperative that health professionals do not neglect this condition, and be prepared to discuss sexual function with patients and their partners, providing them with adequate counseling and pertinent information. ${ }^{13,41,42,45}$ According to the 


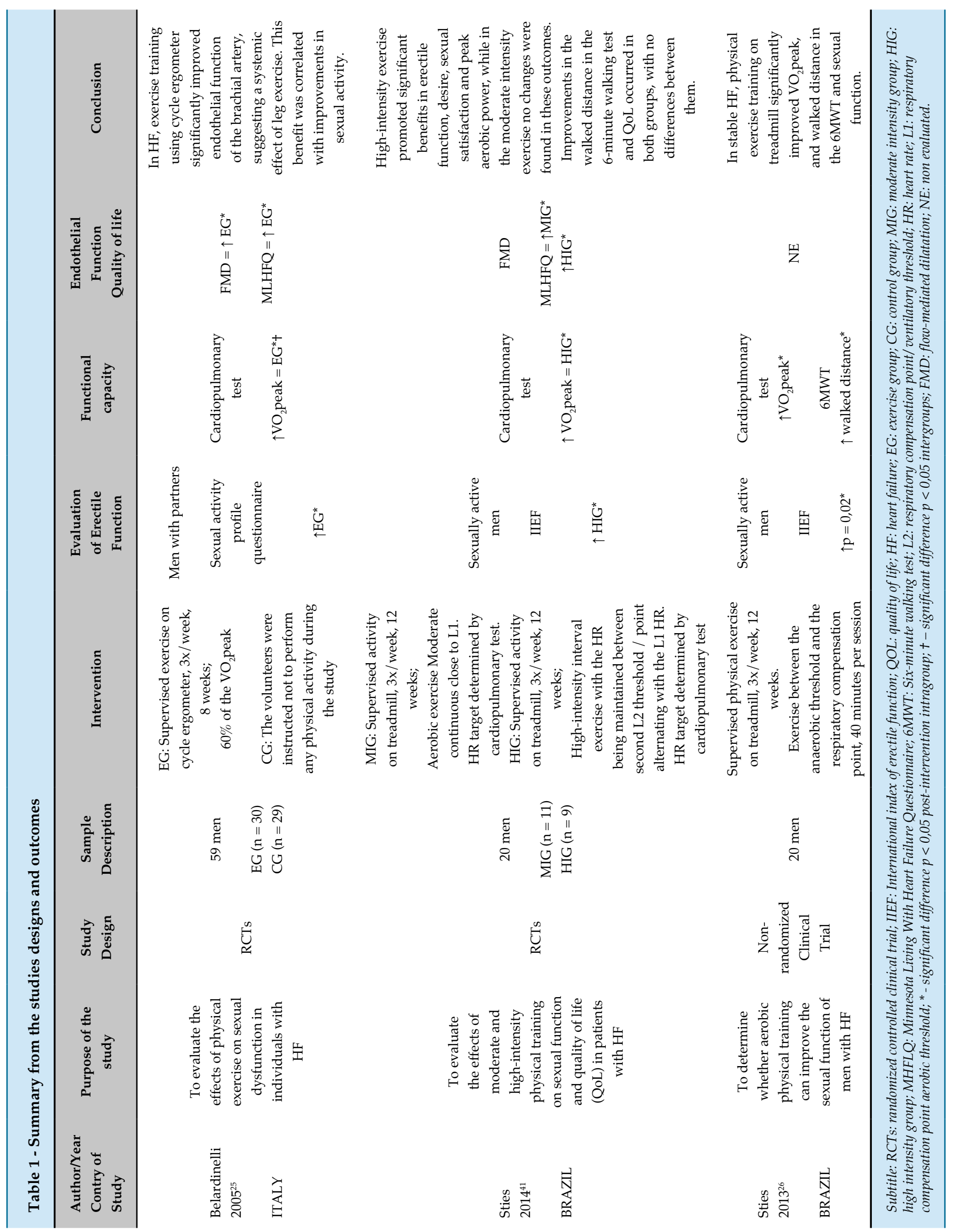


Table 2 - Studies classification according to the Testex scale (maximum score of 15 points)

\begin{tabular}{|c|c|c|c|}
\hline \multirow{2}{*}{ TESTEX Items } & \multicolumn{3}{|c|}{ Authors } \\
\hline & Belardinelli et al (2005) $)^{25}$ & Sties et al $(2013)^{26}$ & Sties et al (2014) $)^{4 c}$ \\
\hline 1 - Eligibility criteria specified & Yes & Yes & Yes \\
\hline 2 - Randomization specified & Yes & Not & Yes \\
\hline 3 - Allocation concealment & Yes & Not & Yes \\
\hline 4-Groups similar at baseline & Yes & Not & Yes \\
\hline Blinding of all participants* & Not & Not & Not \\
\hline Blinding of all therapists* & Not & Not & Not \\
\hline $\begin{array}{l}5 \text { - Blinding of assessor (for at least one key } \\
\text { outcome) }\end{array}$ & Not & Not & Not \\
\hline $\begin{array}{l}6 \text { - Outcome measures assessed in } 85 \% \text { of } \\
\text { patients\# }\end{array}$ & Yes & Yes & Yes \\
\hline 7 - Intention-to-treat analysis & Not & Not & Not \\
\hline $\begin{array}{l}8 \text { - Between-group statistical comparisons } \\
\text { reported }^{\text {a }}\end{array}$ & Yes & Not & Yes \\
\hline $\begin{array}{l}9 \text { - Point measures and measures of variability } \\
\text { for all reported outcome measures }\end{array}$ & Yes & Yes & Yes \\
\hline 10 - Activity monitoring in control groups & Yes & Not & Yes \\
\hline 11 - Relative exercise intensity remained constant & Yes & Yes & Yes \\
\hline 12 - Exercise volume and energy expenditure & Yes & Yes & Yes \\
\hline Total score TESTEX & 12 & 6 & 12 \\
\hline
\end{tabular}

European Society of Cardiology (Guideline ESC 2016), management of sexual dysfunction of patients with $\mathrm{HF}$ should consider the educational status of the patients, who should be informed about sexual behavior, its relationship with $\mathrm{HF}$, and how to treat ED when it exists. ${ }^{46}$

For this purpose, physical exercise should always be recommended. ${ }^{17-21}$ According to the results obtained in this systematic review, a physical exercise program is considered effective in the treatment of ED in HF patients, promoting a significant improvement in erectile function scores $^{25,26,40}$ and QoL ${ }^{25,40}$ in individuals with functional class II and III (NYHA). Studies have shown that physical exercise is a safe and effective therapy for ED, even for patients with more severe impairment, which may be an additional motivation to exercise for $\mathrm{HF}$ patients.
Although ED treatment in these patients may involve the use of PDE-5 inhibitors, this class of drugs is safe only in patients with functional class I and II (NYHA) and is contraindicated in high-risk patients or patients taking nitrates. ${ }^{47}$

In relation to the pathophysiology of ED and HF, two pathways of neurovascular activation have been suggested to be responsible for the association between these conditions. ${ }^{25,48-51}$ These pathways would explain the reduced capacity of penile arterial dilation caused by inadequate blood inflow to the corpus cavernosum, making penile stiffening and enlargement impossible for a satisfactory erection in HF patients. This could contribute to the greater activation of the sympathetic nervous system, which would increase smooth muscle 
tone of the penis and consequent vasoconstriction of the penial vessels. ${ }^{5,11,48}$ In this view, we showed that therapies that can modulate neurovascular activation pathways in patients with HF and ED are promising, including physical exercise.

By evaluation of endothelial function, the study developed by Belardinelli et al., ${ }^{25}$ demonstrated that there was a significantly greater improvement in FMD to the brachial artery in the group of patients with ED submitted to the 8-week exercise protocol compared to controls. In this study, FMD was the strongest independent factor related to the improvement of the sexual function of these patients, who showed a significant improvement in the quality of penile erection. In the study of Sties et al., ${ }^{40}$ the FMD of the brachial artery showed no significant change after 12 weeks of intervention. The difference in these results may have occurred due to differences in the methods used for endothelial function evaluation.

Belardinelli et al., ${ }^{25}$ evaluated FMD by application of $240 \mathrm{mmHg}$ of pressure in the cuff for 4.5 minutes in the dominant upper limb of the patient. The measurements were performed after the use of sublingual nitroglycerin, 30 s, and 90 s after deflation. In the study by Sties et al., ${ }^{40}$ the pressure used was $250 \mathrm{mmHg}$, for 5 minutes, in the left upper limb and the image obtained was captured 50 seconds after the deflation.

The presence of peripheral hypoperfusion in HF patients with impaired $\operatorname{LVEF}^{3,5,48,52}$ contributes to aggravate $\mathrm{ED},{ }^{4,10,11}$ worsening functional status and exercise tolerance. ${ }^{5,53-55}$ The symptoms of HF (dyspnea, fatigue, and exercise intolerance) are among the main factors responsible for impairing sexual function. ${ }^{5,13}$

The results of this review demonstrated that physical exercise in different intensities was able to promote significant improvement in functional capacity and tolerance to exercise in patients with HF and ED when evaluated by cardiopulmonary test. In the study by Sties et al., ${ }^{40}$ the improvement of exercise tolerance in cardiopulmonary exercise test was evidenced only in subjects submitted to high-intensity interval exercise in comparison to those submitted to moderate-intensity exercise. These findings are in agreement with the studies that recommend the use of high-intensity physical training for patients with HF. ${ }^{22,24}$ However, all the patients with ED assessed by the 6MWT showed a significant improvement in the walked distance after the intervention, regardless of exercise intensity.

\section{Limitations}

Among the limitations of this study, there is the small number of participants. Only one study included a physically inactive control group, and only one complete article was included in the review. These limitations make it difficult to carry out a quantitative analysis and show a large gap in the literature.

Additionally, because of the scarcity of data about this relevant topic in the clinical area, further studies should be encouraged to confirm the findings.

\section{Conclusion}

In this systematic review, physical exercise was recommended as a safe and effective therapy to improve $\mathrm{EF}$, endothelial function, quality of life and functional capacity of individuals with ED and heart failure.

\section{Author contributions}

Conception and design of the research: Gonzáles AI, Carvalho T, Andreato LV, Sties SW, Souza AC. Acquisition of data: Gonzáles AI, Carvalho T, Andreato LV, Sties SW, Souza AC. Analysis and interpretation of the data: Gonzáles AI, Carvalho T, Andreato LV, Sties SW, Souza AC. Critical revision of the manuscript for intellectual content :Gonzáles AI, Carvalho T, Andreato LV, Sties SW, Souza AC.

\section{Potential Conflict of Interest}

No potential conflict of interest relevant to this article was reported.

\section{Sources of Funding}

There were no external funding sources for this study.

\section{Study Association}

This article is part of the thesis of doctoral submitted by Ana Gonzáles, from Universidade Estadual de Santa Catarina.

\section{Ethics approval and consent to participate}

This article does not contain any studies with human participants or animals performed by any of the authors. 


\section{References}

1. Sties SW, Andreato LV, de Carvalho T, Gonzáles AI, Angarten VG, Ulbrich AZ, et al. Influence of exercise on oxidative stress in patients with heart failure. Heart Fail Rev. 2018;23(2):225-35.

2. Dixon DL, Griggs KM, Besrten AD, Pasquale CG. Systemic inflammation and cell activation reflects morbidity in chronic heart failure. Cytokine. 2011;56(3):593-9

3. Schwarz ER, Rastogi S, Kapur V, Sulemanjee N, Rodriguez JJ. Erectile dysfunction in heart failure patients. J Am Coll Cardiol. 2006;48(6):1111-9.

4. Zeighami Mohammadi S, Shahparian M, Fahidy F, Fallah E. Sexual dysfunction in males with systolic heart failure and associated factors. ARYA atherosclerosis. 2012;8(2):63-9.

5. Alberti L, Torlasco C, Lauretta L, Loffi M, Maranta F, Salonia A, et al. Erectile dysfunction in heart failure patients: a critical reappraisal. Andrology. 2013;1(2):177-91.

6. Gandaglia G, Briganti A, Jackson G, Kloner RA, Montorsi F, Montorsi P, et al. A systematic review of the association between erectile dysfunction and cardiovascular disease. Eur Urol. 2014;65(5):968-78.

7. Nascimento ER, Maia AC, Pereira V, Soares-filho G, Nardi AE, Silva AC. Sexual dysfunction and cardiovascular diseases: a systematic review of prevalence. Clinics. 2013;68(11):1462-8.

8. Apostolo A, Vignati C, Brusoni D, Cattadori G, Contini M, Veglia F, et al. Erectile dysfunction in heart failure: correlation with severity, exercise performance, comorbidities, and heart failure treatment. J Sex Med. 2009;6(10):2795-805.

9. Wong HT, Clark AL. Impact of reported sexual dysfunction on outcome in patients with chronic heart failure. Int J Cardiol. 2013;170(2):e48-50.

10. Jaarsma T. Sexual problems in heart failure patients. Eur J Card Nurs. 2002;1(1):61-7.

11. Baraghoush A, Phan A, Willix RD Jr, Schwarz ER. Erectile dysfunction as a complication of heart failure. Curr Heart Fail Rep. 2010;7(4):194-201.

12. Hoekstra T, Jaarsma T, Sanderman R, van Veldhuisen DJ, Lesman-Leegte I. Perceived sexual difficulties and associated factors in patients with heart failure. Am Heart J. 2012;163(2):246-51.

13. Jaarsma T. Sexual function of patients with heart failure: facts and numbers. ESC Heart Fail. 2017;4(1):3-7.

14. Hoekstra T, Lesman-Leegte I, Luttik ML, Sanderman R, van Veldhuisen DJ, Jaarsma T. Sexual problems in elderly male and female patients with heart failure. Heart. 2012;98(22):1647-52.

15. Steinke EE. How can heart failure patients and their partners be counseled on sexual activity ? Curr Heart Fail Rep. 2013;10(3): 262-9.

16. NIH. Consensus Conference. Impotence. NIH Consensus Development Panel on Impotence. JAMA. 1993;270(1):83-90.

17. Bocchi EA, Marcondes-Braga FG, Ayub-Ferreira SM, Rohde LEP, Oliveira WA, Almeida DR, et al. Sociedade Brasileira de Cardiologia. III Diretriz Brasileira de Insuficiência Cardíaca Crônica. Arq Bras Cardiol. 2009;93(1 supl.1):1-71.

18. Piña IL, Apstein CS, Balady GJ, Belardinelli R, Chaitman BR, Duscha BD, et al. Exercise and heart failure: a statement from the American Heart Association Committee on exercise, rehabilitation, and prevention Circulation. 2003;8(107):1210-25

19. Perk J, De Backer G, Gohlke H, Graham I, Reiner Z, Verschuren M, et al. European Guidelines on cardiovascular disease prevention in clinical practice (version 2012). The Fifth Joint Task Force of the European Society of Cardiology and Other Societies on Cardiovascular Disease Prevention in Clinical Practice (constituted by representatives of nine societies and by invited experts). Eur Heart J. 2012;33(13):1635-701.

20. WRITING COMMITTEE MEMBERS, Yancy CW, Jessup M, Bozkurt B, Butler J, Casey DE Jr, et al. 2013 ACCF/AHA guideline for the management of heart failure: a report of the American College of
Cardiology Foundation/American Heart Association Task Force on practice guidelines. Circulation. 2013;128(16):e240-327.

21. Ponikowski P, Voors AA, Anker AD, Bueno H, Cleland JG, Coats AJ, et al. 2016 ESC Guidelines for the diagnosis and treatment of acute and chronic heart failure: The Task Force for the diagnosis and treatment of acute and chronic heart failure of the European Society of Cardiology (ESC). Developed with the special contribution of the Heart Failure Association (HFA) of the ESC. Eur J Heart Fail. 2016;18(8):891-975.

22. Vromen T, Kraal JJ, Kuiper J, Spee RF, Peek N, Kemps HM. The influence of training characteristics on the effect of aerobic exercise training in patients with chronic heart failure: a meta-regression analysis. Int J Cardiol. 2016 Apr 1;208:120-7.

23. Sandri M, Viehmann M, Adams V, Rabald K, Mangner N, Hollriegel $\mathrm{R}$, et al. Chronic heart failure and aging - effects of exercise training on endothelial function and mechanisms of endothelial regeneration: results from the Leipzig Exercise Intervention in Chronic heart failure and Aging (LEICA) study. Eur J Prev Cardiol. 2016;23(4):349-58.

24. Angadi SS, Mookadam F, Lee CD, Tucker WJ, Haykowsky MJ, Gaesser GA. High-intensity interval training vs. moderate-intensity continuous exercise training in heart failure with preserved ejection fraction: a pilot study. J Appl Physiol. 2015;119(6):753-8.

25. Belardinelli R, Lacallaprice F, Faccenda E, Purcaro A, Perna G. Effects of short-term moderate exercise training on sexual function in male patients with chronic stable heart failure. Int J Cardiol. 2005;101(1):83-90.

26. Sties SS, Gonzáles AIG, Marques TM, Ulbrich AZU, Angarten VGA, Schmitt AS, et al. Effects of exercise training on sexual function in male with heart failure. Eur Heart J. 2013;34(suppl 1):P5817.

27. Nunes RB, Alves JP, Kessler LP, Dal lago P. Aerobic exercise improves the inflammatory profile correlated with cardiac remodeling and function in chronic heart failure rats. Clinics. 2013;68(6):876-82.

28. Meirelles LR, Matsuura C, Resende AC, Salgado AA, Pereira NR, Coscarrelli PG, et al. Chronic exercise leads to antiaggregant, antioxidant and anti-inflammatory effects in heart failure patients. Eur J Prev Cardiol. 2014;21(10):1225-32

29. Roveda F, Middlekaupf HR, Rondon UM, Reis SF, Souza M, Nastari L, et al. The effects of exercise training on sympathetic neural activation in advanced heart failure a randomized controlled trial. J Am Coll Cardiol. 2003;42(5):854-60.

30. Groehs RV, Toschi-Dias E, Antunes-Correa LM, Trevizan PF, Rondon MU, Oliveira P, et al. Exercise training prevents the deterioration in the arterial baroreflex control of sympathetic nerve activity in chronic heart failure patients. Am J Physiol Heart Circ Physiol. 2015;308(9):H1096-102

31. Hsu CY, Hsieh PL, Hsiao SF, Chien MY. Effects of exercise training on autonomic function in chronic heart failure: systematic review. BioMed Res Int. 2015;2015:591708

32. Cacciatore F, Amarelli C, Ferrara N, Della Valle E, Curcio F, Liguori I, et al. Protective effect of physical activity on mortality in older adults with advanced chronic heart failure: a prospective observational study. Eur J Prev Cardiol. 2019;26(5):481-8.

33. Sun LY, Tu JV, Coutinho T, Turek M, Rubens FD, McDonnell L, et al. Sex differences in outcomes of heart failure in an ambulatory, populationbased cohort from 2009 to 2013. CMAJ. 2018;190(28):E848-54.

34. Snoek JA, Eijsvogels TMH, Van 't Hof AWJ, Prescott E, Hopman $\mathrm{MT}$, Kolkman E, et al. Impact of a graded exercise program on VO2peak and survival in heart failure patients. Med Sci Sports Exerc. 2018;50(11):2185-91.

35. Ding R. Exercise-based rehabilitation for heart failure: clinical evidence. Adv Exp Med Biol. 2017;1000:31-49.

36. Eyre V, Lang CC, Smith K, Jolly K, Davis R, Hayward C, et al. Rehabilitation enablement in chronic heart failure-a facilitated self-care 
rehabilitationintervention in patients with heart failure with preserved ejection fraction (REACH-HFpEF) and their caregivers: rationale and protocol for a single-centre pilot randomised controlled trial. BMJ Open. 2016;6(10):e012853.

37. Moher D, Liberati A, Tetzlaff J, Altman DG. PRISMA Group. Preferred reporting items for systematic reviews and meta-analyses: the PRISMA statement. PLoS Med. 2009;6(7):e1000097.

38. Wespes E, Amar E, Eardley I, Giuliano F, Hatzichristou D, Hatzimouratidis K. Diretrizes Para Disfunção Sexual Masculina: Disfunção Erétil e Ejaculação Prematura [internet]. [acesso em 31 maio 2019]. Disponível em: https: / / uroweb.org/ wp-content/ uploads/MaleSexual-Dysfunction-2012-pocket.pdf.

39. Smart NA, Waldron M, Ismail H, Giallauria F, Vigorito C, Cornelissen $\mathrm{V}$, et al. Validation of a new tool for the assessment of study quality and reporting in exercise training studies: TESTEX. Int J Evid Based Healthc. 2015;13(1):9-18

40. Sties SW, Gonzáles AI, Ulbrch AZ, Mara LS, Neto AS, Bundchen DC, et al. Effects of moderate and high intensity aerobic training on sexual function and quality of life in patients with chronic heart failure. Eur Heart J. 2014;35:61-62.

41. Gupta BP, Murad MH, Clifton MM, Prokop L, Nehra A, Kopecky SL. The effect of lifestyle modification and cardiovascular risk factor reduction on erectile dysfunction: a systematic review and meta-analysis. Arch Intern Med. 2011;171(20):1797-803

42. Driel AG, Hosson MJ, Gamel C. Sexuality of patients with chronic heart failure and their spouses and the need for information regarding sexuality. Eur J Cardiovasc Nurs. 2014;13(3) 227-34.

43. Levine GN, Steinke EE, Bakaeen FG, Bozkurt B, Cheitlin MD, Conti JB, et al. Sexual activity and cardiovascular disease: a scientific statemen from the American Heart Association. Circulation. 2012;125:1058-72.

44. Fischer S, Bekelman D. Gender differences in sexual interest or activity among adults with symptomatic heart failure. J Palliat Med. 2017;20(8):890-4

45. Stein R, Hohmann CB. Sexual activity and heart. Arq Bras Cardiol. 2006;86(1):61-7.
46. Ponikowski P, Voors AA, Anker SD, Bueno H, Cleland GF, Coats AJS et al. 2016 ESC Guidelines for the diagnosis and treatment of acute and chronic heart failure: The Task Force for the diagnosis and treatment of acute and chronic heart failure of the European Society of Cardiology (ESC). Eur Heart J. 2016;37(27):2129-2200.

47. Al-almeri H, Kloner RA. Erectile dysfunction and heart failure: the role of phosphodiesterase type 5 inhibitors. Int J Impot Res. 2009;21(3):149-57.

48. Rodrigues FL, Lopes RA, Fais RS, de Oliveira L, Prado CM, Tostes RC, et al. Erectile dysfunction in heart failure rats is associated with increased neurogenic contractions in cavernous tissue and internal pudendal artery. Life Sci. 2016 Jan 15;145:9-18.

49. Carneiro FS, Zemse S, Giachini FSC, Carneiro ZN, Lima VV, Webb RC, et al. TNF- $\alpha$ infusion impairs corpora cavernosa reactivity. J Sex Med. 2009;6(suppl 3):311-9.

50. Carneiro FS, Webb RC, Tostes RC. Emerging role for TNF- $\square$ in erectile dysfunction. J Sex Med. 2010;7(12):3823-34

51. Matos G, Hirotsu C, Alvarenga TA, Cintra F, Bittencourt L, Tulif S, et al. The association between TNF- a and erectile dysfunction complaints. Andrology. 2013;1(6):872-8.

52. Rodrigues FL, Fais RS, Tostes RC, Carneiro FS. There is a link between erectile dysfunction and heart failure: it could be inflammation. Curr Drug Targets. 2015;16(5): 442-50.

53. Drexler H, Riede U, Miinzel T, Kdnig H, Funke E, Just H. Alterations of skeletal muscle in chronic heart failure. Circulation. 1992;85(5): 1751-9.

54. Fu TC, Chou SL, Chen TT, Wang CH, Chang HH, Wang IS. Central and peripheral hemodynamic adaptations during cardiopulmonary exercise test in heart failure patients with exercise periodic breathing. Int Heart J. 2015;56(4):432-8

55. Barroco AC, Sperandio PA, Reis M, Almeida DR, Neder JA. A practical approach to assess leg muscle oxygenation during rampincremental cycle ergometry in heart failure. Braz J Med Biol Res. 2017;50(12):e6327.
Appendix I: Search Strategy at PubMed and Cochrane-Library

[("Heart Failure" OR “Congestive Heart Failure” OR "Cardiac Failure") AND ("Exercise" OR "Exercise Therapy" OR "Aerobic Exercise" OR "Physical Exercise" OR “High-Intensity Interval Training" OR “HighIntensity Interval Training" OR "Resistance Training" OR "Strength Training") AND ("Erectile Dysfunction" OR "Sexual Dysfunction, Physiological" OR "Penile Erection" OR "Genital Diseases, Male" OR “Impotence" OR “Sexual Dysfunction, Physiological”)] 